\title{
Research on the controllability and energy saving of the pneumatic direct drive system
}

\author{
Hongwang Du*, Wei Xiong, Chi Xu, Zhong'ai Jiang
}

Ship Electromechanical Equipment Institute, Dalian Maritime University, Dalian 116026, China

Email: duhw_1984@dlmu.edu.cn

\begin{abstract}
Aiming at the problem of large air consumption in traditional circuits, this paper proposes a new type of pneumatic circuit, which uses the high-pressure gas produced by the actuator to achieve energy conservation. First, the directly-driven pneumatic circuit of the small-sized air compressor is designed, and the corresponding closed circuit experimental table is set up. Second, the mathematical model of the system is established, the input and output of the air compressor are fitted with the least square method, and the transfer function of the system is derived. Third, the transfer function of the system is determined through parameter identification of the small air compressor system, and the time response and frequency response characteristics of the system are analyzed. Finally, the fuzzy PID controller is designed and the simulation and speed control experiment of the system under different working conditions are carried out. The research shows that compared with traditional circuit, the directly driven system of small air compressor can save $70 \%-74 \%$ of air consumption.
\end{abstract}

Keywords: Pneumatic Energy Saving, Directly Driven System, System Identification, PID Control, Fuzzy PID Control.

\section{INTRODUCTION}

As one of the most important roles in factory automation, the pneumatic system has been widely used in industrial production [1-3]. However, the low efficiency of the pneumatic system impedes its wilder application. From the perspective of efficiency and energy loss, the pneumatic system is much less efficient than the hydraulic system and electrical system. Its efficiency is only $20 \%$, which is far from meeting people's demands for energy conservation and environmental protection at the age when resources are lacking [4-6]. Therefore, energy conservation and environmental protection are drawing more and more attention from the government and the state and it is also imperative to save energy in pneumatic systems. How to improve the efficiency of the system is an important task of pneumatic enterprises, which is of great significance to protect the environment and improve the economic benefits of enterprises [7-9].

Currently, there are mainly three methods for energy conservation of the pneumatic system: dual pressure air supply pneumatic energy saving circuit, exhaust reclaiming pneumatic energy saving circuit, and pneumatic energy saving circuit with separate control of air inflow and outflow. The basic principle of the dual pressure air supply pneumatic energy saving circuit is to change the hardware connection of the pneumatic components on the basis of the traditional pneumatic circuit, so that the air supply pressure of the piston on its trip is different from that on its return trip, i.e. highpressure air supply is adopted during the work process of the cylinder and small-pressure air supply is adopted during the no-load return trip of the cylinder. Beater $\mathrm{P}$ has an overflow valve connected in the rod port to make the inlet pressure of the rod port below the maximum pressure set by the overflow valve, so that the air supply pressure of the cylinder piston during its return trip is lower than the air supply pressure during the trip. The system can save about $25 \%$ of energy [10]. The same method has also been applied on the vertical experiment table. The air is subject to larger pressure when the piston moves up. At this time, the load is jacked up. The air supply pressure is reduced when the piston moves downward. The gravity of the load can be used to do work, so that the piston can move to its lowest point. This method can save the compressed air of about $75 \%$ [11]. The exhaust reclaiming pneumatic energy saving circuit refers to collecting the compressed air that has already been applied for reuse. Li TC collected the compressed air into the gas tank. There are three gas tanks: one is the air supply tank, and one is used to collect the air discharged from the exhaust cavity. These gases are stored in another gas tank after being pressurized by the pressure increasing valve [12]. Aimin Yang et al. [13] improved the traditional servo pneumatic system. They used a two-position two-way electromagnetic valve to connect the two cavities of the cylinder. The compressed air in the two cavities is exchanged through controlling the electromagnetic valves. The precise positioning of the system is achieved on 
the basis of energy conservation through combining the control strategies of the sliding valve and the bypass valve. $10.9 \%-29.5 \%$ of the compressed air can be saved [13-15]. Jihong Wang et al. designed the pneumatic energy saving circuit with separate control of air inflow and outflow. By using the tracking control strategy, the piston motion acceleration is obtained through calculating the pressure difference of the two cavities. The acceleration is fed back into the system to control the size of the opening of the two proportional valves. Therefore, the air inflow and outflow can be controlled and the experimental system can complete the required actions according to the precomputed velocity curve. About 3\%-7\% of compressed air can be saved [16]. Harris P [17] believed that the conventional pneumatic circuits failed to take advantage of the expansion energy stored in the compressed air and just used the transferred energy. How to make full use of the expansion energy of the compressed gas to do work has become a hot research topic to improve the efficiency of the pneumatic system currently. A variable pressure control method based on the bridge type circuit was put forward to improve the utilization efficiency of the compressed air. The genetic algorithm is adopted for dynamic optimization, which can save $29 \%$ of air amount per trip [17].

Among the abovementioned three kinds of pneumatic system, the researches on the dual pressure pneumatic circuit and the exhaust reclaiming and reuse pneumatic circuit are relatively mature. The research on the pneumatic circuit with separate control of air inflow and outflow is new. Although its tracking control is fairly precise, it can only save $3 \%-7 \%$ of the compressed air. The energy-saving effect is not significant. Subsequent researchers proposed the bridge type circuit which can achieve separate control of the air intake and exhaust. Although the energy-saving effect is sound, with $50 \%-70 \%$ of energy saved, the system is rather complicated and the convergence and the accuracy of the optimization algorithm cannot be guaranteed. It only works when the single working condition is changed.

Aiming at the problem of large air consumption of traditional circuit, a new type of closed pneumatic circuit is proposed based on the idea of the bridge circuit. The small air pump is directly connected to the head and tail of the cylinder. The operation of the cylinder can be controlled directly by controlling the revolving speed of the motor and no large-sized air compressor is required. Energy saving is achieved on the basis of the directly driven pneumatic system. After the circuit is tested and improved, the time response and performance of the system is analyzed. Experiments show that the directly driven system of the air compressor can achieve good energy saving effect. Compared with the bridge circuit, it is easy to be implemented, and the speed control performance is better. It is of great significance for the application of the pneumatic system.

\section{PNEUMATIC DIRECTLY DRIVEN SYSTEM}

The design of the circuit follows the idea of exhaust reutilization. Starting from the perspective of closed circuit, a small-sized commutating air compressor is connected to both the head and the tail of the cylinder. The high-pressure air already produced in the actuator is recycled and the exhaust phase is deleted. Meanwhile, the small-sized air pump is adopted to directly drive the actuator. Since there is no such commutating gas pump with big enough flow pressure, the plunger pump and reversing valve are combined. The principle diagram of the circuit of the small air compressor direct drive system is shown in Figure 1

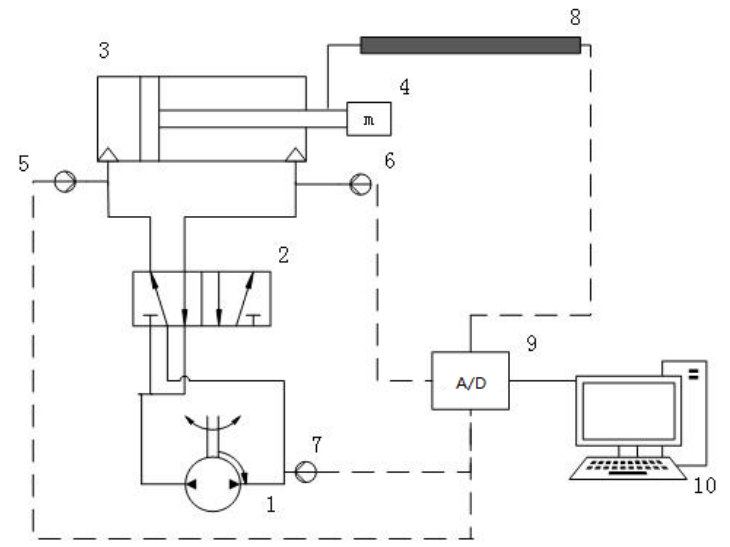

1. Compressor 2. Reversing valve 3. Cylinder 5,6. Pressure sensor 7 . Flow sensor 8. Displacement sensor 9. DAQ Card 10. IPC

Figure 1. Circuit diagram of the pneumatic system of the small-sized air compressor

The corresponding experiment table was set up based on the circuit diagram shown in Figure 1, which is shown in Figure 2 .

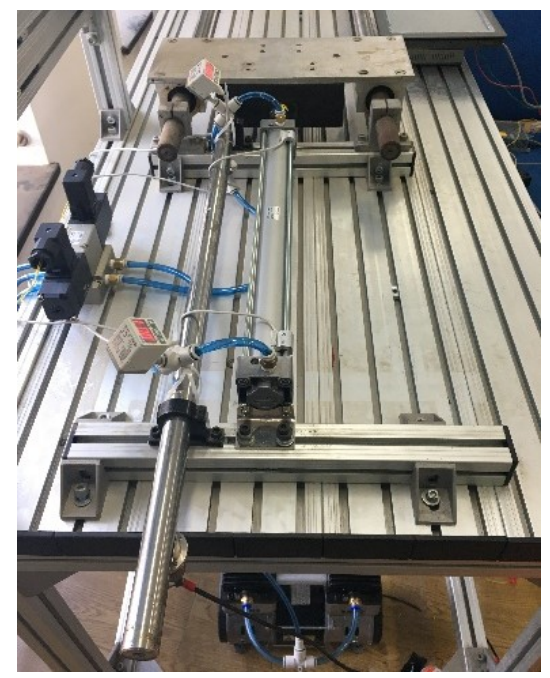

Figure 2. Experiment table of the small air compressor system

The experiment table is composed of two parts: pneumatic circuit and measurement and control circuit. The former includes air compressor, two-position five-way solenoid valve, cylinder and pipeline. When the motor starts, extract air at one side and discharge air at the other side, and the piston rod will be driven. When the piston rod moves to the cylinder end, the two-position five-way electromagnetic valve commutates under the control of the magnet ring. Then, the piston rod moves towards the opposite direction. The measurement and control circuit include pressure sensor, displacement sensor, flow sensor, data acquisition card and industrial personal computer. Each sensor collects the signal of each parameter in the operation of air compressor and cylinder. The data acquisition card converts the signal into the data that can be identified by the computer, and then the data is transferred to the industrial control machine. The machine figures out the 
control signal data required by the air compressor at this moment based on certain control algorithm. Then, the data is transferred to the data collection card. The data collection card converts these data to voltage signals which will be transferred to the air compressor to drive the cylinder and complete corresponding functions. The acceptance and processing of the input signal, realization of the control algorithm, and the input signal transmission inside the industrial personal computer are all realized through setting up corresponding modules using MATLAB/Simulink.

\section{SYSTEM MATHEMATIC MODEL}

In order to analyze the motion characteristics and stability of the direct drive system of the small air compressor and achieve sound control results, it is necessary to model and analyze the system. The modelling of the small air compressor system is performed in this section.

According to the law of conservation of energy and the ideal gas state equation, the pressure differential equation of the two cavities of the cylinder is obtained [18]:

$$
\begin{aligned}
& \frac{d P_{a}}{d t}=\frac{k}{V_{a}}\left(R T Q_{m a}-P_{a} \frac{d V_{a}}{d t}\right) \\
& \frac{d P_{b}}{d t}=\frac{k}{V_{b}}\left(R T Q_{m b}+P_{b} \frac{d V_{b}}{d t}\right)
\end{aligned}
$$

where,

$P_{a}, P_{b}$ - pressure of the air intake cavity and exhaust cavity, $\mathrm{Pa}$;

$k$-ratio of specific heats;

$V_{a}, V_{b}$-volume of the air intake cavity and exhaust cavity, $\mathrm{m}^{3}$;

$R$ - constant volume of the air, $287 \mathrm{~J} /(\mathrm{kg} \cdot \mathrm{K})$;

$T$-air temperature, $\mathrm{K}$;

$Q_{m a}, Q_{m b}$ - mass flow rate of the air intake cavity and exhaust cavity, $\mathrm{kg} / \mathrm{s}$;

where, the volume of the two cavities of the cylinder is expressed as follows:

$$
\begin{aligned}
& V_{a}=A_{a}\left(x_{a 0}+y\right) \\
& V_{b}=A_{b}\left(x_{b 0}+L-y\right)
\end{aligned}
$$

where:

$A_{\mathrm{a}}, A_{\mathrm{b}}$ - the effective working area of the air in the air intake cavity and exhaust cavity, $\mathrm{m}^{3}$;

$x_{\mathrm{a} 0}, x_{\mathrm{b} 0}$ - length of the dead zone in the air intake cavity and exhaust cavity, m;

$L$ - total journey of the cylinder, $\mathrm{m}$;

$y$ - piston displacement, $\mathrm{m}$

The heat insulation and air discharge in the exhaust cavity of the cylinder is treated as the isentropic process and the temperature change inside the square-cavity is [19]:

$$
T=T_{0}\left(\frac{P_{b}}{P_{b 0}}\right)^{k-1 / k}
$$

where:

$T_{0}$-initial temperature of the exhaust cavity, $\mathrm{K}$;

$P_{\mathrm{b} 0}$-initial pressure of the exhaust cavity, $\mathrm{Pa}$.

The piston motion equation is obtained based on Newton's second law [20]:

$M \frac{d^{2} y}{d t^{2}}=\left(P_{a} A_{a}-P_{b} A_{b}\right)-F_{f}$

where:

$M$ - total mass of piston and moving parts, $\mathrm{kg}$;

$F_{f}$-frictional resistance, N.

The friction force during the cylinder movement is a variable, which is related to the cylinder structure, pressure of the two cavities, load size and other conditions. In this paper, the classical empirical formula of the static friction force + coulomb friction + viscous friction force is adopted:

$F_{f}= \begin{cases}\left(F_{c}+F_{v}\right) \cdot \operatorname{sgn}(v), & |v|>0 \\ F_{s} & ,|v|<0\end{cases}$

$F_{v}=B_{v} \cdot|v|$

where:

$F_{c}$ - coulomb friction, $\mathrm{N}$;

$F_{v}$-viscous friction, $\mathrm{N}$

$F_{s}$-static friction force, $\mathrm{N}$

$B_{v}$ - coefficient of viscous friction, $\mathrm{N} \cdot \mathrm{s} / \mathrm{m}$.

The flow of the gas through the valve port is determined by the effective circulation area of the valve port and the upstream and downstream pressure of the valve port. The flow characteristics of the pneumatic system can be described by the sonic conductance and the critical pressure ratio. The mass flow equation of the system is shown in the following formula:

$Q_{m}=C_{v} \rho_{0} P_{u} \omega(\sigma, b)$

$\varphi(\sigma, \mathrm{b})= \begin{cases}1 & \sigma=\frac{p_{\mathrm{d}}}{p_{\mathrm{u}}}<b \\ \sqrt{1-\left(\frac{\sigma-b}{1-b}\right)^{2}} & \sigma=\frac{p_{\mathrm{d}}}{p_{\mathrm{u}}} \geq b\end{cases}$

where:

$C_{v}$ - sonic conductance, $\mathrm{m}^{3} / \mathrm{s} \cdot \mathrm{MPa}$

$P_{u}, P_{b}$ - upstream and downstream pressure of the component, $\mathrm{MPa}$.

$\rho_{0}$ - density of air under standard conditions, $\mathrm{kg} / \mathrm{m}^{3}$;

$b$-critical pressure ratio, 0.2 ;

$\sigma$-pressure ratio.

Unlike the traditional valve-controlled cylinder system, the driving part of the small air compressor system is the air pump, and the input and output of the air pump directly affect the output of the system. According to the vacuum system pumping equation, the continuity equation and the vacuum technology basic equation, the following formula can be obtained: 
$V_{b} \frac{d P_{b}}{d t}=Q P_{b}$

$$
Q=Q_{s}\left(1-\frac{P_{s}}{P_{b}}\right)
$$

The relationship between the flow and pressure of the vacuum pump can be obtained through combining 11 and 12:

$V_{b} \frac{d P_{b}}{d t}=Q_{s}\left(1-\frac{P_{s}}{P_{b}}\right) P_{b}$

where:

$Q$ - the actual extraction flow of the air pump, $\mathrm{L} / \mathrm{min}$;

$Q_{s}$ - theoretical extraction flow of the air pump, L/min;

$P_{s}$ - extreme pressure of the air pump, $\mathrm{MPa}$

$Q_{s}$ in formula 12 and 13 are the theoretical extraction flow of the air pump. It is related to the input voltage of the air compressor. The relationship between the input voltage $U$ and the air pump output flow is obtained by adopting the curve fitting method. The relational expression is as follows:

$$
f(x)=0.3342 x^{3}-7.569 x^{2}+51.82 x-13.11
$$

where, $x$ is the input voltage of the air compressor and is the output flow of the air pump.

The system transfer function can be derived based on the above formula. The transfer function between the output displacement and the input voltage of the system is:

$$
G(x)=\frac{y(s)}{u(s)}=\frac{K_{v} \omega_{n}^{2}}{s\left(s^{2}+2 \xi \omega_{n} s+\omega_{n}^{2}\right)}
$$

where:

$K_{v}$ - system speed gain, $m^{2} /(s \cdot V \cdot K)$;

$\omega_{n}$-system inherent frequency, $\mathrm{rad} / \mathrm{s}$;

$\xi$ - system damping ratio.

The parameters are expressed as follows:

$K_{v}=\frac{K_{q} T R\left(A_{a} V_{b}+A_{b} V_{a}\right)}{P_{a} A_{a}^{2} V_{b}+P_{b} A_{b}^{2} V_{a}}$

$\omega_{n}=\sqrt{\frac{k\left(P_{a} A_{a}^{2} V_{b}+P_{b} A_{b}^{2} V_{a}\right)}{M V_{a} V_{b}}}$

$\xi=\frac{B_{v}}{2} \sqrt{\frac{V_{a} V_{b}}{M k\left(P_{a} A_{a}^{2} V_{b}+P_{b} A_{b}^{2} V_{a}\right)}}$

\section{SYSTEM IDENTIFICATION}

Although many hypotheses and simplifications have been made in the process of modeling and linearization of small air compressor systems, there are still uncertain parameters in the derived transfer function model. In order to accurately reflect the dynamic characteristics of the controlled object, an ideal controller is designed to conduct systematic identification research on the model.

The selection of input signals is very important to the identification results of the system parameters. In order to make the system recognizable, it is necessary to ensure that the input signal can fully stimulate all modes of the system. The $\mathrm{M}$ sequence signal is usually used [21]. In this paper, the $3 \mathrm{~Hz}$ $\mathrm{M}$ serial signal with the signal range of $0.5-3.5 \mathrm{~V}$ is adopted. It is shown in Figure 3.

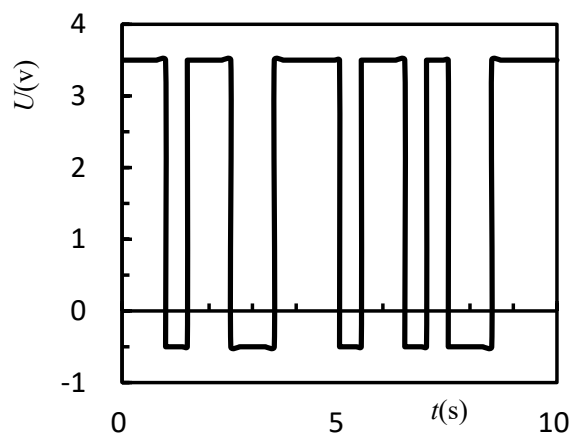

Figure 3. M sequence signal

Through system identification, the transfer function is shown as below:

$G(s)=\frac{41.5}{s\left(s^{2}+6.7 s+69.2\right)}$

According to formula (19), the performance parameters of the system can be calculated as follows:

$K_{v}=0.6, \omega_{n}=8.32, \xi=0.4$

The frequency-response analysis is a common method to study and analyze the system characteristics. This method can be used to shift the transfer function from the complex domain to the frequency domain with clear physical significance to analyze the system performance. The frequency characteristic analysis is performed to equation (19) to study the Bode diagram of the system transfer function. It is found that the amplitude margin and phase margin of the system are both positive, suggesting that the system is stable. However, the phase margin is too big, indicating long system response time. This is mainly caused by the starting time of the motor.

\section{FUZZY PID CONTROL}

Because of the delay of the system, it is difficult for the traditional PID controller to achieve ideal control effect. In addition, the transfer function of the system also changes as the working condition changes. Therefore, $K_{p}, K_{i}$ and $K_{d}$ in PID need to be reset. It takes a lot of time to carry out parameter setting on the experimental table and may cause damage to the hardware. Considering the stability and accuracy of the system operation, the control strategy of fuzzy PID is chosen. It can realize online adjustment of PID parameters, effectively enhancing the dynamic performance and steady-state performance of the control system [22].

First, the input and output were confirmed. The deviation e and deviation variation rate $e_{c}$ of the small air compressor system are taken as the input of the fuzzy controller and the 
parameters of $K_{p}, K_{i}$ and $K_{d}$ of PID are taken as the output. According to the operation characteristics of the pneumatic system, the fuzzy control rules adopted in this paper are as follows:

1) When the cylinder is started, the displacement deviation of the piston rod is rather large. The relatively large $K_{p}$ can be chosen to speed up the response. Meanwhile, in order to avoid the possibility that the control function is beyond the scope of permission due to the differential oversaturation caused by the transient enlarging of deviation e at the beginning, the medium value of $K_{d}$ is chosen. In order to prevent the integral saturation caused by the overshooting of the piston displacement, the integral saturation is generated, the integral function is usually removed, i.e. $K_{i}=0$.

2) When the cylinder runs normally and the values of the displacement deviation e and the variation rate $e_{c}$ are medium, in order to make the piston displacement have a small overshooting, $K_{p}$ should be smaller. The value of $K_{i}$ shall be appropriate. At this time, the trend of $K_{d}$ has a relatively large impact on the system response. Its value shall be proper to ensure the response speed of the system.

3) When the cylinder movement is basically stable, the displacement deviation e is relatively small. In order to ensure the system stability, $\mathrm{K}_{p}$ and $\mathrm{K}_{i}$ shall be added. The value of $\mathrm{K}_{d}$ is very important to avoid the oscillation of the system near the set value and to the anti-disturbance performance of the system. When the deviation variation rate $e_{c}$ is small, $\mathrm{K}_{d}$ shall be larger, and it shall be smaller when $e_{c}$ is big. Based on the above rules, a suitable fuzzy rule table is established (The fuzzy logic toolbox in MATLAB is invoked). Then, the fuzzy rules table of the three set parameters of $\mathrm{K}_{p}, \mathrm{~K}_{i}$ and $\mathrm{K}_{d}$ are obtained respectively, and the fuzzy controller for reasoning and judgment are obtained.

The subordinating degree function of each fuzzy subset and the fuzzy control model of each parameter are adopted to design the fuzzy matrix table of PID parameters using the fuzzy synthetic reasoning. The corrected parameters are found out and substituted into the following formula:

$K_{p}=K_{p}^{\prime}+\Delta K_{p}$

$K_{i}=K_{i}^{\prime}+\Delta K_{i}$

$K_{d}=K_{d}^{\prime}+\Delta K_{d}$

where, $K_{p}^{\prime}, K_{i}^{\prime}$, and $K_{d}^{\prime}$ are the values before modification. During the process of online operation, the online selfcorrection of PID parameters are completed through the processing of fuzzy logic rules, checking tables and calculations, and the parameter value for each moment is formed. The fuzzy PID controller simulation program is set up in MATLAB/Simulink. The input signal is the step signal. The parameters of the transfer function in the controlled system are changed. In addition, $\omega_{n}$ of the system is changed within certain range and separate simulation is carried out. The response curves corresponding to different $\omega_{n}$ are obtained, which are shown in Figure 4. It can be seen from the curve that the change of the system transfer function does not affect the control effect, suggesting the adaptivity of the fuzzy PID controller.

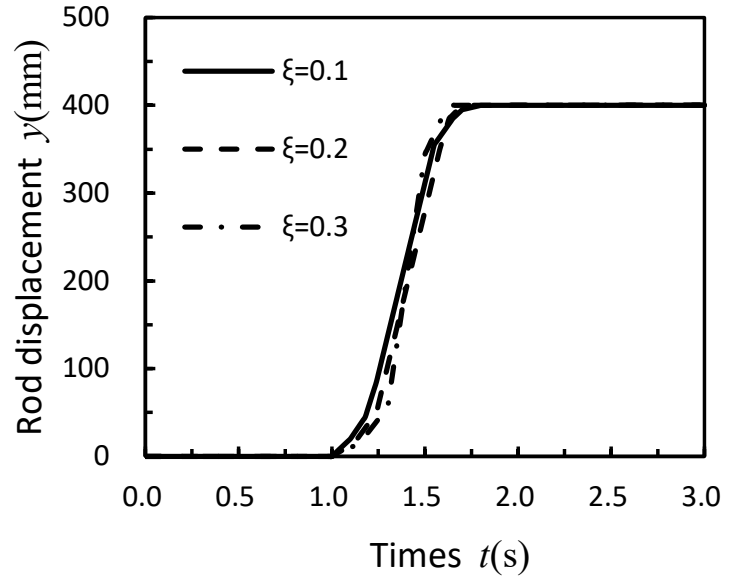

Figure 4. Step response curve for different $\omega_{n}$

\section{EXPERIMENT VALIDATION}

On the basis of theory and simulation analysis, this section carries out experiments on the experiment tables and conducts control verification based on fuzzy PID control system under different working conditions. The energy saving of small air compressor system is also studied with a comparison with the traditional circuit. The fuzzy PID controller was designed in MATLAB/Simulink to further verify the availability of small air compressor system, and experiment verification was carried out in different working conditions. The experimental procedure is shown in Figure 5.

\subsection{Experimental results under different loads}

The set signal remains to be the step signal. The response curve of the piston rod under different mass loads is determined by changing the mass load. Figure 5 shows the cylinder operation response curve under different mass load.

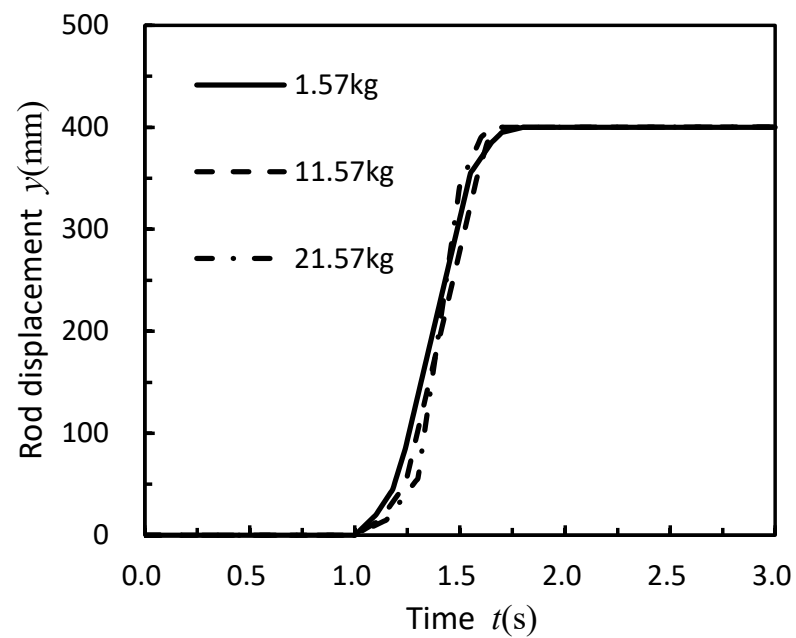

Figure 5. Displacement curve under different loads

It can be seen that with the change of the mass load, the average speed of the cylinder operation will change somewhat, but has not departed from the trend of the input signal, and there is no significant difference among the output displacements corresponding to different masses under the 
fuzzy PID adjustment. In addition, there is no impingement phenomenon at the trip destination, suggesting sound control effect. It is suggested that the fuzzy PID is applicable to the variable system load, and is more ideal than the traditional PID control in terms of the control effect.

\subsection{Drive test results of high power air compressor}

In order to explore the applicability of the small air compressor system, the air compressor used in the experiment table was replaced by a high-power air compressor with a power of 1,500 W. The maximum air flow and the maximum working pressure of the air compressor are $153.3 \mathrm{~L} / \mathrm{min}$ and $0.9 \mathrm{MPa}$ respectively. In the small air compressor system, the air compressor is the core, so high power will have a big impact on the operation of the system. The response time of the system shortens and the system operation will be more stable. The input signal is step signal to verify the time response of the system. The system's displacement response is shown in Figure 6.

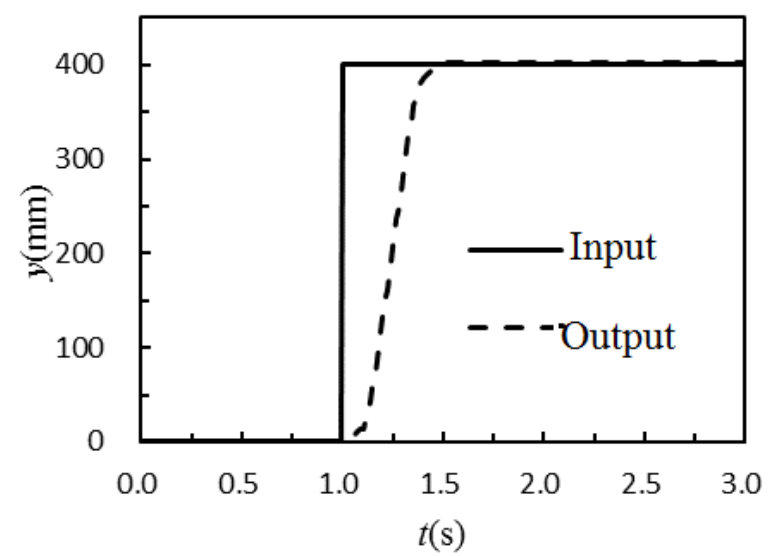

Figure 6. The displacement response curve of the highpower air compressor

It is shown in Figure 6 that the time response of high power air compressor is faster than that of small power air compressor. By changing the slope of the step signal, the displacement response curve of the cylinder piston with different signals is shown in Figure 7.

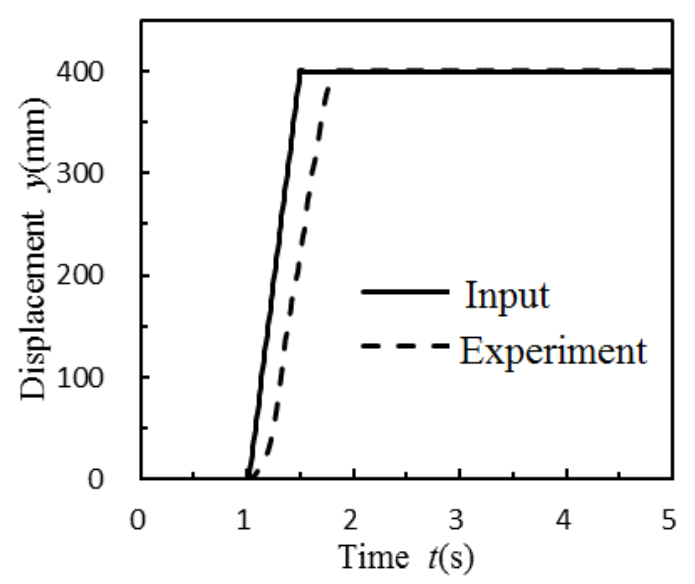

(a) Time response curve when the rise time is $0.5 \mathrm{~s}$

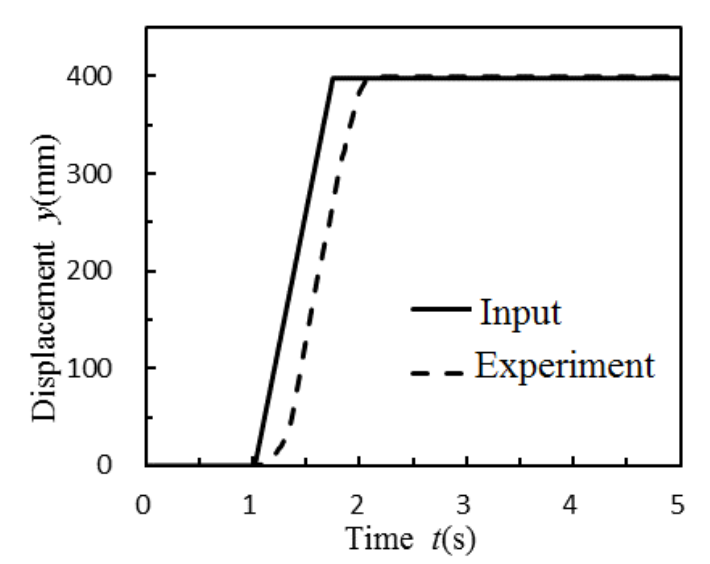

(b) Time response curve when the rise time is $0.75 \mathrm{~s}$

Figure 7. Curve of the step signal under different slopes

It can be seen from Figure 7 that, with the change of the set signal of the system, the cylinder displacement can make corresponding response. The set signal is kept to be the step signal. By changing the mass load, the response curve of the piston rod under different mass load is measured. Figure 8 shows the operation response curve of the cylinder under different mass loads.

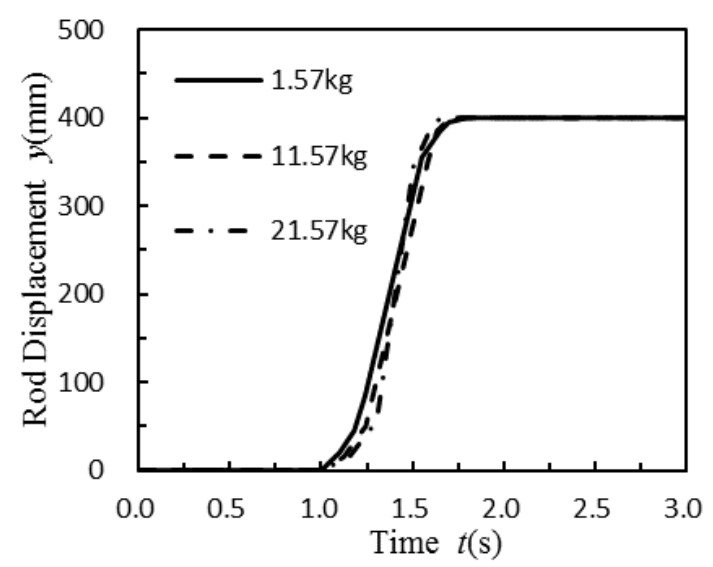

Figure 8. Curve of system displacement under different loads

According to Figure 8, in the case of changing the system load, the controller can adapt to the system, and changes following the trend of the input signal. When the speed of the piston reaches $1.48 \mathrm{~m} / \mathrm{s}$, the speed does not go up further, because the cylinder stroke is too short. The experimental curve shows that the controller based on fuzzy PID has stable adaptability. In order to verify the control effect of the system when multiple working conditions are changing simultaneously, experimental study on the various operating conditions (when the rise time of the step signal is $1 \mathrm{~s}$ and the load quality changes between 0 and $20 \mathrm{~kg}$ ) was carried out. The experimental results show that the displacement of the cylinder can follow the input signal trend, suggesting that the controller achieves good control and realizes self-adaptation control.

\subsection{Energy-saving analysis}

The air consumption is expressed with the volume which is 
changed to the standard state. The traditional circuit pushes the cylinder movement with the high-pressure air provided by the gas tank which is used to storage the compressed air, while the small air compressor system directly produces compressed air through motor revolving to push the cylinder movement. Therefore, the small air compressor system mainly consumes electricity. Since the air consumption is expressed with volume, rather than energy, when it is adopted to express the energy consumption, it needs to be converted using specific power or specific energy of the compressor. The specific power refers to the average consumption of electricity required for outputting a unit volume flow of the compressed air and the specific energy means the average power consumption required for outputting a unit volume of the compressed air

$\alpha=\frac{W}{V}$

where,

$\alpha$-specific energy of the air compressor, $\mathrm{Wh} / \mathrm{L}$;

$W$ - power consumption of using air compressor for an hour, Wh;

$V$-rated air consumption of the air compressor, L.

The consumption of compressed air by the equipment is changed to the volume flow of the air at the entrance of the compressor. The air consumption of the traditional circuit can be calculated by the following equation:

$Q=Q_{A N R} \frac{P_{A N R}}{P}$

where,

$Q$-volume flow in the atmosphere, $\mathrm{L} / \mathrm{min}$;

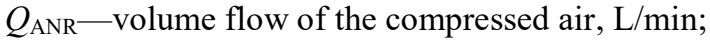

$P$-atmospheric pressure, $\mathrm{MPa}$;

$P_{\mathrm{ANR}}$ - rated pressure of air compressor, $\mathrm{MPa}$.

The gas consumption of the pneumatic driving system proposed in this paper is obtained by the flow curve integral of the exhaust outlet of the air pump. The flow curve of the air pump (the small-power air compressor) is shown in Figure 9.

The gas consumption of the traditional circuit and pneumatic direct drive system is calculated according to the working condition experiment carried out in the first two sections, which are shown in Table 1.

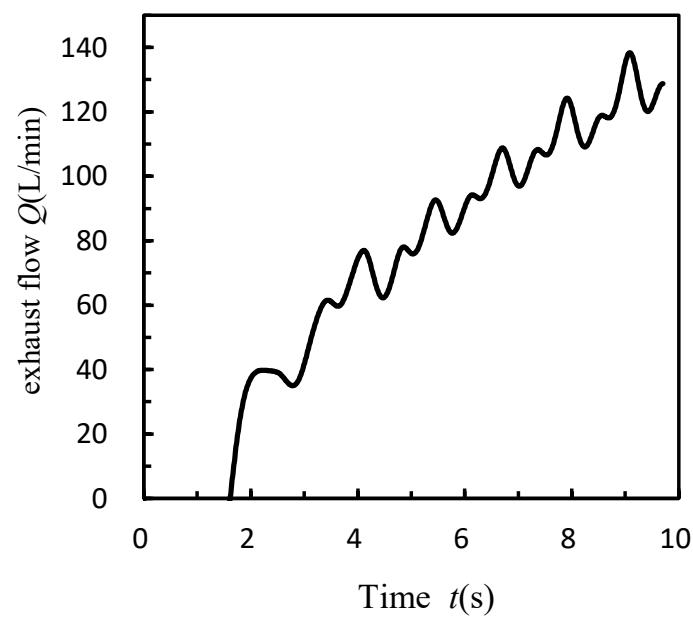

Figure 9. Flow output curve of the air compressor
Table 1. Comparison of gas consumption in different working conditions

\begin{tabular}{|c|c|c|c|c|}
\hline $\begin{array}{c}\text { Air } \\
\text { supply } \\
\text { pressure } \\
(\mathrm{MPa})\end{array}$ & $\begin{array}{c}\text { Load } \\
{[\mathrm{kg}]}\end{array}$ & $\begin{array}{c}\text { Air } \\
\text { consumption } \\
\text { of drive } \\
\text { circuit } \\
\text { [L] }\end{array}$ & $\begin{array}{c}\text { Air } \\
\text { consumpt } \\
\text { ion of } \\
\text { direct } \\
\text { drive } \\
\text { system } \\
{[\mathrm{L}]}\end{array}$ & $\begin{array}{c}\text { Energy } \\
\text { saving } \\
\text { rate }\end{array}$ \\
\hline 0.3 & 1.57 & 3.23 & 0.94 & $70.85 \%$ \\
\hline 0.3 & 11.57 & 4.54 & 1.23 & $72.87 \%$ \\
\hline 0.3 & 21.57 & 5.69 & 1.45 & $74.57 \%$ \\
\hline
\end{tabular}

\section{CONCLUSIONS}

From the perspective of efficiency, the pneumatic system is much less efficient than the hydraulic system and electrical system in terms of efficiency and energy loss. Its efficiency is only $20 \%$. Aiming at this problem, a new type of closed pneumatic circuit is put forward in this paper. It uses the highpressure gas generated to do work to achieve energy saving. The circuit of small-sized air compressor is designed, and the corresponding experimental table is set up to conduct research on the system's speed control performance. Without controlling the circuit with speed, the speed of the pneumatic circuit can be controlled by controlling the revolving speed of the air compressor's motor. The mathematical model of the system is established and parameter identification is carried out. According to the Bode diagram of the system, the system performance is analyzed. Although it is stable, the start-up time of the built-in motor of the air compressor leads to slow response. In view of this problem, the fuzzy PID controller is designed and simulation is carried out based on the identified transfer function. The simulation results show that the proposed fuzzy PID control strategy has sound effect and certain adaptivity. Systematic experiments are carried out on the set experiment table of the small air compressor under different working conditions to verify the controllability of the system and the availability of the controller. The analysis of the experimental results shows that the trace performance of the small direct drive control system is fairly sound and compared with traditional circuit, the system can save 70\%-74\% of air consumption.

The small air compressor system proposed in this paper can realize energy saving on the basis of stable control. However, there are still many deficiencies, so the research in this paper is only a few preliminary attempts. There are still many researches that need to be done.

1) Currently, the experimental study of the small air compressor system is only done to the single cylinder of the air compressor, and the application scope of the small air compressor direct-drive system needs further verification.

2) The air compressor meeting the performance requirement of the circuit system proposed in this paper needs to be developed.

\section{ACKNOWLEDGMENT}

The work in this paper was supported by the National Natural Science Foundation of China (51175053) and the Fundamental Research Funds for the Central Universities of 
China (3132016353 and 3132016073) and Liaoning Provincial Natural Science Foundation of China (201601068).

\section{REFERENCES}

[1] Bunse K., Vodicka M., Schönsleben P., Brülhart M., Ernst F.O. (2011). Integrating energy efficiency performance in production management - Gap analysis between industrial needs and scientific literature, Journal of Cleaner Production, Vol. 19, No. 6, pp. 667-679.

[2] Lund H., Mathiesen B.V., Connolly D., Østergaarda P.A. (2014). Renewable energy systems - A smart energy systems approach to the choice and modelling of $100 \%$ renewable solutions, Chemical Engineering Transactions, Vol. 39, No. 4, pp. 1-6.

[3] Yang A., Pu J., Wong C.B., Moore P. (2009). By-pass valve control to improve energy efficiency of pneumatic drive system, Control Engineering Practice, Vol. 17, No. 6, pp. 623-628.

[4] Carrera-Chapela F., Donoso-Bravo A., González J.A., Ruiz-Filippi G. (2016). Air emissions from a sludge thickener: Dynamic data for air quality models, Chemical Engineering Transactions, Vol. 54, No.1, pp. 151-156.

[5] Yusop, Mohd M.Y. (2006). Energy saving for pneumatic actuation using dynamic model prediction, Cardiff University, USA.

[6] Saidur R., Rahim N.A., Hasanuzzaman M. (2010). A review on compressed-air energy use and energy savings, Renewable \& Sustainable Energy Reviews, Vol. 14, No. 4, pp. 1135-1153.

[7] Shaw D., Yu J.J., Cheng C. (2013). Design of a Hydraulic motor system driven by compressed air, Energies, Vol. 6, No. 7, pp. 3149-3166.

[8] Wernik J., Wolosz K.J. (2014). Modelling and research of heat transfer in fins of the pneumatic pulsator, Chemical Engineering Transactions, Vol. 39, No. 1, pp. 919-924.

[9] Jihong W., Wang J.D., Liau V.K. (2000). Energy efficient optimal control of pneumatic actuator systems, Systems Science, Vol. 26, No. 3, pp. 109-123.

[10] Beater P. (2007). Pneumatic Drives, System Design, Modelling and Control, Springer Press, Berlin, pp. 183207.

[11] Harris P., O’Donnell G.E., Whelan T. (2012). Energy efficiency in pneumatic production systems, state of the art and future directions, Leveraging Technology for a Sustainable World, Vol. 26, No. 3, pp. 363-368.

[12] Li T.C., Wu H.W., Kuo M.J. (2007). A study of gas economizing pneumatic cylinder, Journal of Physics, Conference series, Vol. 48, No. 5, pp. 1227-1232.

[13] Yang A., Pu J., Wong C.B., Moore P. (2009). By-pass valve control to improve energy efficiency of pneumatic drive system, Control Engineering Practice, Vol. 17, No. 13, pp. 623-628.

[14] Blagojevic V., Šešlija D., Stojiljković M., Dudić S. (2013). Efficient control of servo pneumatic actuator system utilizing by-pass valve and digital sliding mode, Indian Academy of Sciences, Vol. 38, No. 7, pp. 187-197.

[15] Shen X., Goldfarb M. (2007). Energy saving in pneumatic servo control utilizing interchamber crossflow, Journal of Dynamic Systems, Measurement, and Control, Vol. 129, No. 6, pp. 303-310.

[16] Wang J., Gordon T. (2012). Energy optimal control of servo-pneumatic cylinders through nonlinear static feedback linearization, Journal of Dynamic Systems, Measurement, and Control, Vol. 134, No. 1, pp. 1-11.

[17] Harris P., Nolan S., O'Donnell G.E. (2014). Energy optimization of pneumatic actuator systems in manufacturing, Journal of Cleaner Production, Vol. 72, No. 6, pp. 35-45

[18] Li Z., Li J., Yang W., Liang J.B. (2017). The simplified calculation model of pneumatic garbage transportation at acceleration period in horizontal straight pipe, International Journal of Heat and Technology, Vol. 35, No. 1, pp. 683-687.

[19] Ambethkar V., Kumar M. (2017). Numerical solutions of 2-D unsteady incompressible flow with heat transfer in a driven square cavity using stream function-vorticity formulation, International Journal of Heat and Technology, Vol. 35, No. 1, pp. 459-473.

[20] Boubaya N., Saad B., Maazouz M. (2016). Radial active magnetic bearing control using fuzzy logic, Modelling, Measurement and Control A, Vol. 89, No. 10, pp. 92100.

[21] Leonidopoulos G. (2016). Modelling and simulation of electric power transmission line current as wave, Modelling, Measurement and Control A, Vol. 89, No. 1, pp. 1-12.

[22] Dayal P.A.S., Raju G.S.N., Mishra S. (2016). Pattern synthesis using accelerated particle swarm optimization, Modelling, Measurement and Control A, Vol. 89, No. 6, pp. 58-76. 